\title{
Laser induced forward transfer of $\mathrm{SnO} 2$ for sensing applications using different precursors systems
}

\section{Journal Article}

Author(s):

Mattle, Thomas; Hintennach, Andreas; Lippert, Thomas; Wokaun, Alexander

Publication date:

2013-02-01

Permanent link:

https://doi.org/10.3929/ethz-b-000077502

Rights / license:

In Copyright - Non-Commercial Use Permitted

Originally published in:

Journal of Applied Physics 110(2), https://doi.org/10.1007/s00339-012-7472-7 


\title{
Laser induced forward transfer of $\mathrm{SnO}_{2}$ for sensing applications using different precursors systems
}

\author{
Thomas Mattle • Andreas Hintennach • \\ Thomas Lippert • Alexander Wokaun
}

Received: 22 November 2012 / Accepted: 22 November 2012 / Published online: 5 December 2012

(C) Springer-Verlag Berlin Heidelberg 2012

\begin{abstract}
This paper presents the transfer of $\mathrm{SnO}_{2}$ by laser induced forward transfer (LIFT) for gas sensor applications. Different donor substrates of $\mathrm{SnO}_{2}$ with and without triazene polymer (TP) as a dynamic release layer were prepared. Transferring these films under different conditions were evaluated by optical microscopy and functionality. Transfers of sputtered $\mathrm{SnO}_{2}$ films do not lead to satisfactory results and transfers of $\mathrm{SnO}_{2}$ nanoparticles are difficult. Transfers of $\mathrm{SnO}_{2}$ nanoparticles can only be achieved when applying a second laser pulse to the already transferred material, which improves the adhesion resulting in a complete pixel. A new approach of decomposing the transfer material during LIFT transfer was developed. Donor films based on UV absorbing metal complex precursors namely, $\mathrm{SnCl}_{2}$ (acac) $)_{2}$ were prepared and transferred using the LIFT technique. Transfer conditions were optimized for the different systems, which were deposited onto sensor-like microstructures. The conductivity of the transferred material at temperatures of about $400{ }^{\circ} \mathrm{C}$ are in a range usable for $\mathrm{SnO}_{2}$ gas sensors. First sensing tests were carried out and the transferred material proved to change conductivity when exposed to ethanol, acetone, and methane.
\end{abstract}

T. Mattle · A. Hintennach · T. Lippert $(\varangle) \cdot$ A. Wokaun General Energy Research Department, Paul Scherrer Institute, 5232 Villigen PSI, Switzerland e-mail: Thomas.lippert@psi.ch Fax: +41-56-3102199

\section{A. Hintennach}

Electrochemical Layers, Daimler AG (Mercedes-Benz Cars), HPC H152, 70176 Stuttgart, Germany

\section{Introduction}

Highly sensitive and reliable gas sensors are widely used for detecting different gases, e.g., air quality monitoring and safety applications. Tin dioxide as a cheap and nontoxic material is often used in commercial gas sensors. This material is a n-type semiconductor, which can detect various gases by using the conductivity changes of its surface due to adsorption and desorption processes [1]. Different methods such as sputtering or ink jet printing are commercially used to coat $\mathrm{SnO}_{2}$ sensors. Sputtering leads to very smooth and homogeneous films, but for a selective coating of the sensing area additional production steps, for example, photolithographic structuring, are necessary [2]. In recent years, $\mathrm{SnO}_{2}$ sensor fabrication moved toward ink jet printing [3]. This technique is selective and has the possibility of printing a nanostructured surface to improve the sensitivity but with the drawback of using solvents.

Laser induced forward transfer (LIFT) is a solvent free process and capable to transfer different materials with a high lateral resolution [4]. Selective and solvent free printing onto, e.g., single sensors, would improve and simplify the production. It has already been demonstrated that LIFT printing is a versatile technique to transfer active materials onto sensors [5-12].

LIFT printing for gas sensor applications would take advantage of all these benefits. In the following, we show our results on LIFT printing of conductive $\mathrm{SnO}_{2}$ starting from different precursor materials.

\section{Materials and methods}

\subsection{Donor film preparation}

To transfer materials by LIFT, the key factor is to get donor films with the correct architecture to achieve a success- 
ful transfer. An additional triazene polymer (TP) interlayer, which is tailored to absorb the laser light, produces enough energy to transfer various materials. The important parameters for transfers are the thickness of the TP layer and the brittleness of the material; in general transfers without TP are possible if the material absorbs the laser light and produces enough energy for a transfer.

Different methods were tried to prepare homogeneous and transferable $\mathrm{SnO}_{2}$ films starting from sputtered $\mathrm{SnO}_{2}$ and commercial $\mathrm{SnO}_{2}$ nanoparticles (NP) to different metal complex precursor systems. The TP used for the following experiments was synthesized as described in [13, 14]

\subsubsection{Sputtered $\mathrm{SnO}_{2}$}

$\mathrm{SnO}_{2}$ films were deposited by magnetron sputtering from a homemade $\mathrm{SnO}_{2}$ target. A deposition on top of the delicate TP photopolymer is possible using low power $(P=$ $20 \mathrm{~W}, \varnothing=1 \mathrm{in})$ and an inert atmosphere $\left(P_{\text {Argon }}=5 \times\right.$ $10^{-3}$ mbar). This is necessary in order to keep the thermal load on the polymer low and to have a nonoxidative environment. This procedure led to a film thickness of $100 \mathrm{~nm}$ $\mathrm{SnO}_{2}$ on $200 \mathrm{~nm} \mathrm{TP}$.

\subsection{2 $\mathrm{SnO}_{2}$ nanoparticle}

Commercially available $\mathrm{SnO}_{2} \mathrm{NP}(14 \mathrm{wt} \%$ in water) with a nominal particle size of $10-15 \mathrm{~nm}$ were purchased from Alpha Aeser. Donor films were prepared by spin coating (2500 rpm, $60 \mathrm{~s}$ ) the $\mathrm{SnO}_{2}$ NP solution on top of a TP film resulting in a film thickness of $\sim 50 \mathrm{~nm}$. For a good wetting of the TP surface, $\approx 1 \mathrm{wt} \%$ Triton-X 100 (Sigman-Aldrich) was added to the $\mathrm{SnO}_{2} \mathrm{NP}$ solution. This was necessary in order to obtain homogeneous and crack free films.

\subsection{3 $\mathrm{SnCl}_{2}(\mathrm{acac})_{2}$, two different synthetic routes}

$\mathrm{Sn}(\mathrm{IV}) \mathrm{Cl}_{2}$ (acac) $)_{2}$ was synthesized as described in [15]. $1.71 \mathrm{~g} \mathrm{SnCl}_{2}$ was mixed with $1.8 \mathrm{~g}$ acetylacetone and $0.62 \mathrm{~g}$ $\mathrm{HCl}$. Adding $\approx 1 \mathrm{wt} \%$ Triton $\mathrm{X}-100$ is necessary in order to spin coat the solution on TP coated quartz substrates. The solution was filtered with a 1-2 $\mu \mathrm{m}$ glass fiber (GF) filter and spin coated with $2500 \mathrm{rpm}$ resulting to a film thickness of about $900 \mathrm{~nm}$. The freshly spin coated films were exposed to $\mathrm{NH}_{3}$ vapor in order to induce solidification in a controlled way leading to a homogeneous film. In the following, we will call samples prepared by this method $\mathrm{SnCl}_{2}(\mathrm{acac})_{2}-\mathrm{I}$.

A second synthesis route of $\mathrm{Sn}(\mathrm{IV}) \mathrm{Cl}_{2}(\mathrm{acac})_{2}$ as described in [16] was used to prepare LIFT donor substrates. $1.07 \mathrm{~g}$ of $\mathrm{SnCl}_{2}$ was mixed with $6 \mathrm{ml}$ acetone and flushed with $\mathrm{O}_{2}$ for $10 \mathrm{~min}$. The mixture was filtered through a 1$2 \mu \mathrm{m}$ GF filter. Films were spin coated with $2500 \mathrm{rpm}$ on bare quartz as well as on TP with an addition of $\approx 1 \mathrm{wt} \%$ Triton-X 100 resulting in a film thickness of $700 \mathrm{~nm}$.
In the following, we will call samples prepared by this method $\mathrm{SnCl}_{2}$ (acac) $)_{2}$-II.

\subsection{Transfer setup}

LIFT transfer was made with a $\mathrm{XeCl}$ excimer laser (Complex, Lambda Physik, $\lambda=308 \mathrm{~nm}, \tau=30 \mathrm{~ns}$ ). The laser beam was shaped using a square shaped $2 \times 2 \mathrm{~mm}$ or a circu$\operatorname{lar} \varnothing=4 \mathrm{~mm}$ aperture in the homogeneous part of the beam and demagnified four times to ablate pixels of $500 \mu \mathrm{m}$ side length or $\varnothing=1 \mathrm{~mm}$ diameter, respectively. The fluences were adjusted with an attenuation plate and varied between $50 \mathrm{~mJ} / \mathrm{cm}^{2}$ and $500 \mathrm{~mJ} / \mathrm{cm}^{2}$. The donor and the receiver substrate were placed in close contact $(<10 \mu \mathrm{m}[17,18])$ on a motorized translation stage. The described setup is computer controlled. All the transfers were carried out under ambient conditions (atmospheric pressure and $23^{\circ} \mathrm{C}$ ).

\subsection{Sensor pads and conductivity measurements}

For experimental and economical reasons, working with commercially available sensor microstructures is not suitable. Therefore, sensor-like microstructures for LIFT experiments were designed and produced. The electrode structure of a commercial gas sensor (MSGS 3000) was taken as model to fabricate interdigitated electrodes (IDTs) structures with large area side contacts. The IDT structures are made out of $20 \mathrm{~nm}$ chromium with $100 \mathrm{~nm}$ platinum sputtered onto glass. Therefore, the height difference of the IDTs, especially for $\mathrm{SnO}_{2} \mathrm{NP}$ and sputtered $\mathrm{SnO}_{2}$ with a film thickness of $50 \mathrm{~nm}$ and $100 \mathrm{~nm}$, respectively, is considered to be large. $\mathrm{SnO}_{2}$ pixels with a diameter of $1 \mathrm{~mm}$ were deposited onto the samples, covering the whole IDT area and connected manually via the large electrodes of the electrical setup.

In order to condition the samples and decompose the $\mathrm{SnCl}_{2}(\mathrm{acac})_{2}$ to $\mathrm{SnO}_{2}$, the lifted sensor pads were heated for $24 \mathrm{~h}$ at $350{ }^{\circ} \mathrm{C}$ followed by $6 \mathrm{~h}$ at $500{ }^{\circ} \mathrm{C}$ and $6 \mathrm{~h}$ at $600{ }^{\circ} \mathrm{C}$ in a stream of $1 \mathrm{l} / \mathrm{min}$ of synthetic air (SA) containing $20 \% \mathrm{O}_{2}$ and $80 \% \mathrm{~N}_{2}$. For commercial sensors, a conditioning step is also needed in order to achieve a more stable microstructure [19].

The sensor-like pads were mounted onto an alumina block containing a K-type thermocouple, connected with metal clamps pressed onto the Pt electrodes with a intermediate graphite rod to protect the electrodes. The sample was heated inside a tube oven set to $450{ }^{\circ} \mathrm{C}$ and a constant air flow of $51 / \mathrm{min}$ of SA reaching a sample temperature of $400{ }^{\circ} \mathrm{C}$. The resistance and the temperature was measured with a Keithley 2400 Source Meter, Keithley 2000 Multimeter, respectively, controlled via a computer. The sample resistance was determined via a constant bias voltage of $5 \mathrm{~V}$. A constant voltage measurement prevents range changes and $5 \mathrm{~V}$ is a standard voltage used for commercial sensors. 


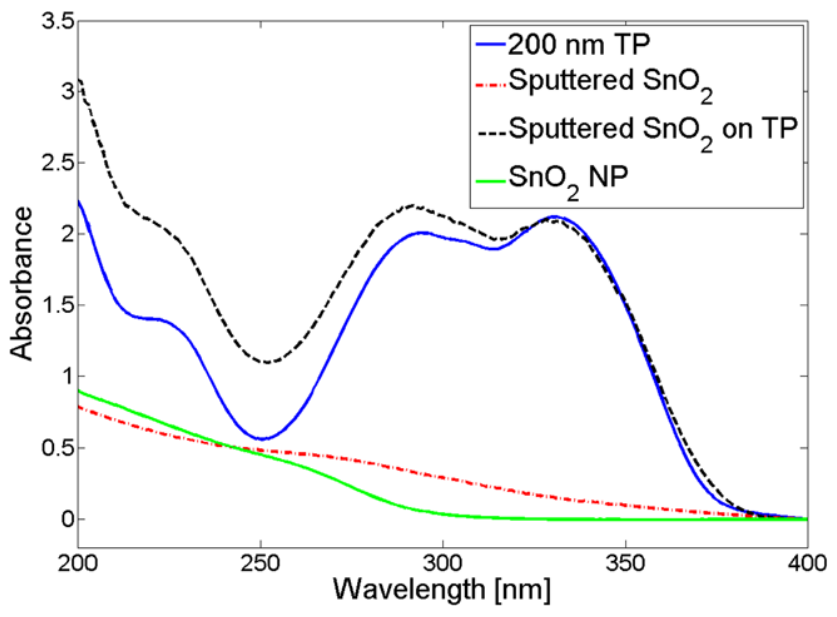

Fig. 1 Absorption curve of TP and different $\mathrm{SnO}_{2}$ donor substrates. The absorption of sputtered $\mathrm{SnO}_{2}$ on TP is the sum of the absorption of TP and pure $\mathrm{SnO}_{2}$ and proves the TP layer is fully functionality after the sputter process

\section{Results and discussion}

In this study, we show the results on preparing different LIFT donors and the transfer of conductive $\mathrm{SnO}_{2}$ pixels. First tests were carried out with sputtered $\mathrm{SnO}_{2}$ as this type of deposition was used on commercial sensors in the past [2]. To increase the active surface on the sensor, which should enhance the sensitivity, films of $\mathrm{SnO}_{2} \mathrm{NP}$ were tested in a second approach. The absorption (Abs) at the laser wavelength $(308 \mathrm{~nm})$ is rather small (see Fig. 1) for thin films of the obtained thickness $d$ (sputtered $\mathrm{SnO}_{2}$ : $d \approx 100 \mathrm{~nm}, \mathrm{Abs}=0.25$ and for $\mathrm{SnO}_{2} \mathrm{NP}: d \approx 50 \mathrm{~nm}$, Abs $=0.02$ ), which makes transfers without the dynamic release layer (DRL) difficult, because transfers of spin coated $\mathrm{NP}$ without TP interlayer damage the quartz donor substrate irreversibly. Spin coating a NP solution containing a surfactant onto TP films is possible. In contrast, sputtering on top of TP is difficult as TP is only thermally stable up to about $100{ }^{\circ} \mathrm{C}$ and decomposes also in an $\mathrm{O}_{2}$ plasma. In this article, we report that sputtering onto TP is possible with the parameters as described in Sect. 2.1.1.

To prove the existence of TP after sputtering a UV-Vis spectrum (Varian Cary 500) shown in Fig. 1 was taken of pure TP, pure $\mathrm{SnO}_{2}$, and of sputtered $\mathrm{SnO}_{2}$ on TP. The absorption curve of $\mathrm{SnO}_{2}$ on TP is clearly the sum of pure TP and $\mathrm{SnO}_{2}$. This fact shows that the TP is fully intact after the sputter process.

A subsequent transfer of these systems showed a sharp and complete ablation of the material, but the transfer onto the receiver was incomplete. Applying a second laser pulse to the ablated area led to complete pixel transfers on the receiver (not shown). Consecutive tests on detecting ethanol were not promising and, therefore, the donor films were changed to increase sensitivity and improve the transfer quality. For an increased sensitivity, a high surface area is desired and transferring a soft material improves the printing quality. Besides using $\mathrm{SnO}_{2} \mathrm{NP}$ new approaches for printing $\mathrm{SnO}_{2}$ gas sensors were also evaluated.

\subsection{Reactive LIFT}

Combining the advantages of spatial printing together with the possibility of decomposing chemical bonds with UV light led to the concept of reactive LIFT. For reactive LIFT, the material to be transferred is desired to get decomposed by the laser light. The material decomposition can be used to propel the transfer and, therefore, a DRL is not necessarily needed. Additionally, soft precursor materials can be chosen in order to improve the transfer quality as well as to tailor the properties of the donor films to get in our case a large surface area.

Films of $\mathrm{SnCl}_{2}$ (acac) $)_{2}$ prepared by the described synthetic methods strongly adsorb at $308 \mathrm{~nm}$ (see Fig. 2) suggesting that a transfer without TP should be possible. For the transfer of $\mathrm{SnCl}_{2}$ (acac) $)_{2}$ films, two strategies were applied: transfers with a single and with a double laser pulse. The interaction of the laser light with the $\mathrm{SnCl}_{2}(\mathrm{acac})_{2}$ might decompose the material and form $\mathrm{SnO}_{2}$. If the $\mathrm{SnO}_{2}$ is not or only partially decomposed, a sensing layer will be achieved by the thermal decomposition of $\mathrm{SnCl}_{2}(\mathrm{acac})_{2}$, which is described in [20].

To determine the amount of decomposed material the two differently prepared $\mathrm{SnCl}_{2}$ (acac) 2 films (see Sect. 2.1.3) without TP were measured with a UV-Vis spectrometer. The absorbance for both films at $308 \mathrm{~nm}$ is larger than 2. Irradiating the films with a fluence below the ablation threshold $\left(25 \mathrm{~mJ} / \mathrm{cm}^{2}\right)$, which is around ten times lower than a possible transfer fluence, changes the absorbance slowly. The effect of the irradiated light is small, but clearly visible after 1,000 pulses whereas the absorbance at longer wavelength increases. Irradiating the samples with 100 and less pulses, the change in absorption is small, but the trend toward higher absorption is already there. A transition from $\mathrm{SnCl}_{2}(\mathrm{acac})_{2}$ to $\mathrm{SnO}_{2}$ should in theory lower the absorbance as bulk $\mathrm{SnO}_{2}$ has a bandgap of $3.6 \mathrm{eV}$ [21] $\left(\lambda=h \cdot c \cdot\left(E_{\text {photon }}\right)^{-1}=\right.$ $344 \mathrm{~nm}$ ).

Contrary to expectations the absorbance increases with increasing number of pulses. This fact indicates that the UVVis spectra show not only the transition of $\mathrm{SnCl}_{2}(\mathrm{acac})_{2}$ to $\mathrm{SnO}_{2}$, but also the change in roughness which induces scattering.

The large amount of pulses needed to change the absorption significantly $(\geq 100 \mathrm{P})$ indicates that the material transition from $\mathrm{SnCl}_{2}$ (acac) $)_{2}$ to $\mathrm{SnO}_{2}$ by the laser light during the transfer for one and two pulse transfers is limited. Therefore, we can assume that most of the material will be transformed to $\mathrm{SnO}_{2}$ during the heating step. In order to transfer the different materials for sensing applications, the best transfer 

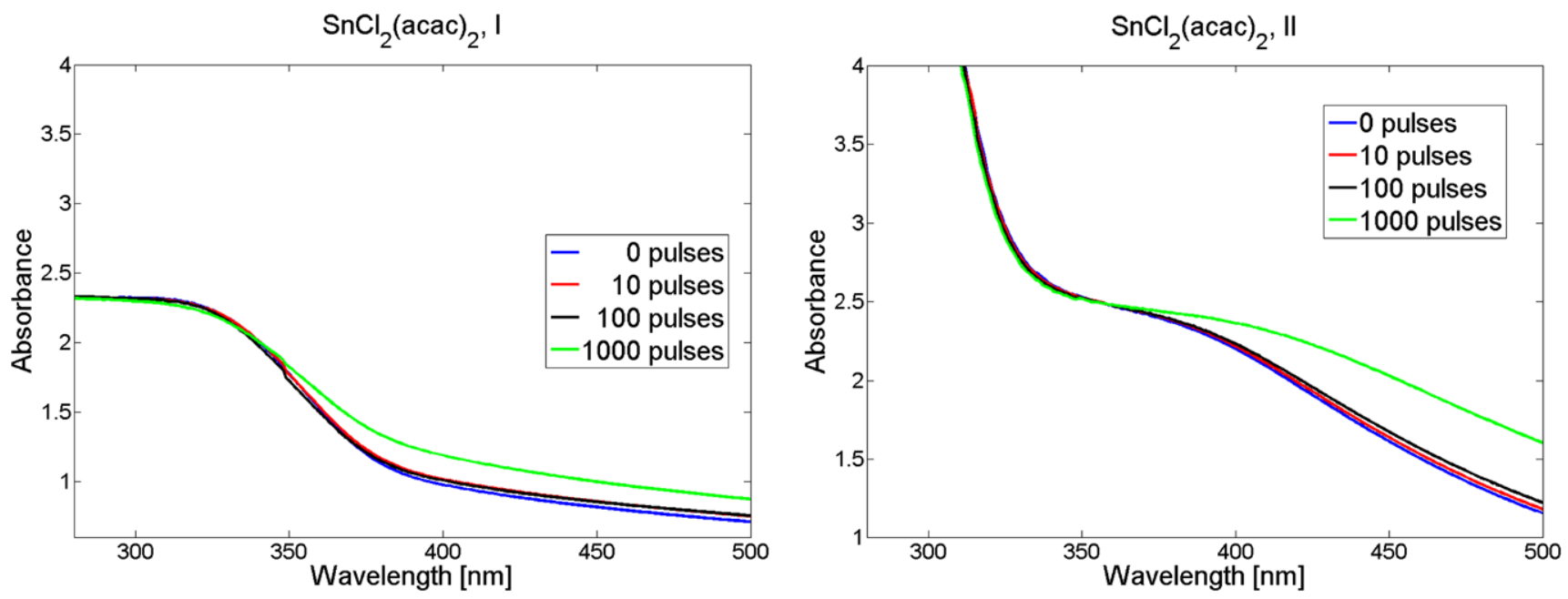

Fig. 2 UV vis spectra of two differently prepared $\mathrm{SnCl}_{2}(\mathrm{acac})_{2}$ films irradiated with a laser below the ablation threshold $\left(25 \mathrm{~mJ} / \mathrm{cm}^{2}\right)$ after 0,10 , 100 , and 1000 laser pulses

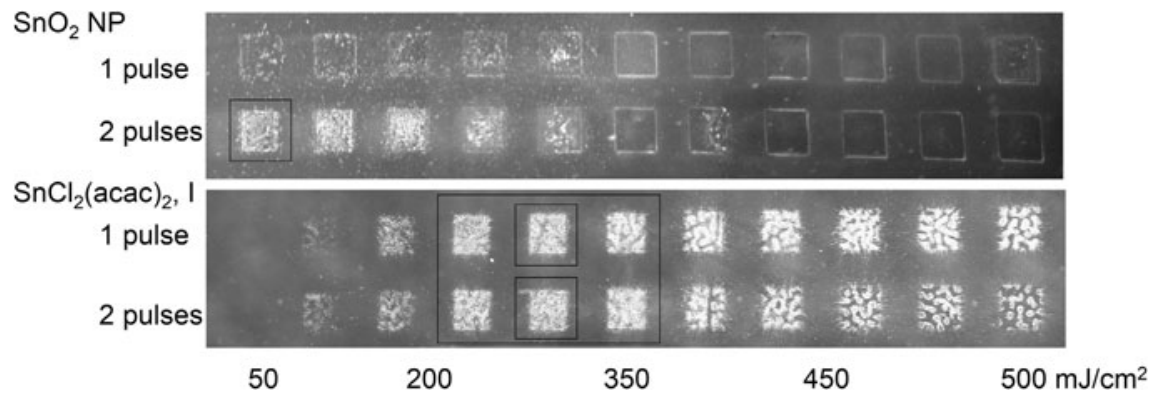

Fig. 3 Images of transfers with one and two laser pulses in the energy range of 50 to $500 \mathrm{~mJ} / \mathrm{cm}^{2}$ of $\mathrm{SnO}_{2}$ nanoparticles and $\mathrm{SnCl}_{2}$ (acac) 2 . Successful transfers for $\mathrm{SnCl}_{2}(\mathrm{acac})_{2}$ in a wide energy range and for

conditions and film composition for each system has to be found.

\subsection{Optimal transfer condition}

All the systems described above were transferred with one and two laser pulses onto a glass substrate in order to determine the best transfer conditions. The transfer quality was rated from the optical appearance under a microscope with a magnification between 0.7 and 7 (see Fig. 3). Transfers were tested in a fluence range of $50 \mathrm{~mJ} / \mathrm{cm}^{2}$ to $500 \mathrm{~mJ} / \mathrm{cm}^{2}$ and various TP thicknesses using no TP, 50, 150, 200, and $350 \mathrm{~nm}$ thick films. Best transfers were achieved with no TP or with a layer thickness of $200 \mathrm{~nm} \mathrm{TP}$, which is also the optimal thickness for the transfer of other materials [22].

Images of laser transfers with one and two laser pulses in the tested fluence range of $\mathrm{SnO}_{2} \mathrm{NP}$ on TP and $\mathrm{SnCl}_{2}$ (acac) $)_{2}$-I are shown in Fig. 3. The upper part of the image shows transfers of $\mathrm{SnO}_{2} \mathrm{NP}$ using a $200 \mathrm{~nm}$ TP interlayer. Comparing the transfers of $\mathrm{SnO}_{2} \mathrm{NP}$ transferred with one pulse (upper row) to a two pulse transfer one and to pulses is possible. $\mathrm{SnO}_{2}$ nanoparticles only transfer with two pulse transfer in a narrow energy window

(lower row) shows that pixels only transfer as a whole for two laser pulses with an optimal transfer fluence of about $50-100 \mathrm{~mJ} / \mathrm{cm}^{2}$. From [23], it is known that the front side ablation rate of TP for $85 \mathrm{~mJ} / \mathrm{cm}^{2}$ is about $200 \mathrm{~nm}$, which is in the range of the optimal transfer fluence. Therefore, we can assume that the TP is decomposed after the first laser pulse. The second laser pulse might heat up the NP, which improves the adhesion on the receiver substrate leading to a completely transferred pixel. For single pulse transfers, some transferred material is visible on the receiver substrate but not as a complete layer. This would also indicate that the layer is delaminated from the donor substrate and only small parts of it stick on the receiver substrate after one laser pulse. For transfer fluences between 100 and $350 \mathrm{~mJ} / \mathrm{cm}^{2}$, small amounts of $\mathrm{SnO}_{2} \mathrm{NP}$ are transferred but not a continuous pixel. The difference between one and two pulses is large as only marginal amounts of material adhere to the receiver using one pulse. Transfers for fluences above $350 \mathrm{~mJ} / \mathrm{cm}^{2}$ do not show large difference between one and two pulse transfers. The laser fluence for this regime is too high and all the material is removed from the irradiated area and only the 
Fig. 4 Transfers of all the different precursor systems under optimal conditions onto glass with transfer fluence $\phi$ and average pixel thickness $h$

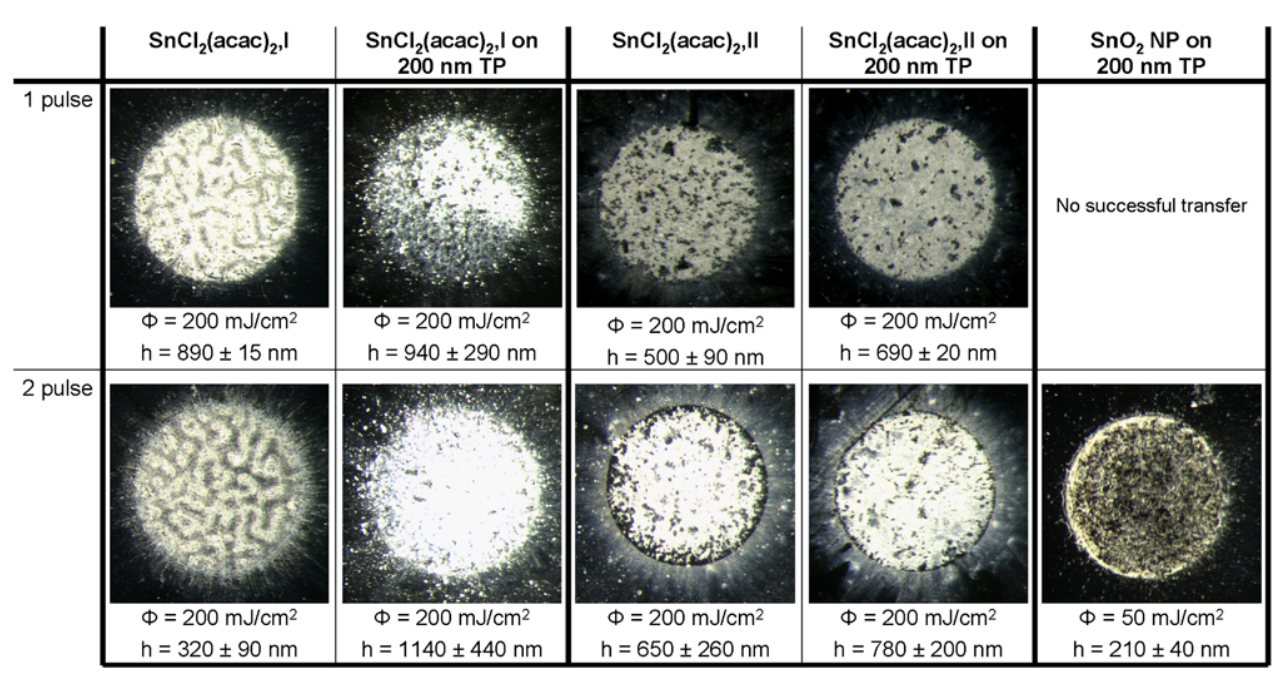

rims of the pixels, where some material may accumulate, are visible.

For comparison, the transfers of a $\mathrm{SnCl}_{2}(\mathrm{acac})_{2}$-I transferred without TP are shown in the lower part of Fig. 3. For this precursor system, transfers with one and with two laser pulses are successful in a wide fluence range of 200 to $350 \mathrm{~mJ} / \mathrm{cm}^{2}$. In the optimal fluence range, the quality of the transferred pixel is comparable for one and two pulse transfers. For all the other systems, which are not shown in Fig. $3, \mathrm{SnCl}_{2}$ (acac) $)_{2}$-I on TP as well $\mathrm{SnCl}_{2}(\text { acac })_{2}$-II with and without TP, successful transfers were achieved in a similar fluence range. The optimal transfer energy for all the systems based on $\mathrm{SnCl}_{2}$ (acac) 2 transferred with and without TP, one and two pulses is 200 to $300 \mathrm{~mJ} / \mathrm{cm}^{2}$ compared to $50 \mathrm{~mJ} / \mathrm{cm}^{2}$ for the $\mathrm{SnO}_{2} \mathrm{NP}$ transfer. This data set shows that for optimized film composition, transfer fluence, and number of pulses it is possible to achieve successful transfers for all the described material systems. Transferring sputtered $\mathrm{SnO}_{2}$ was not successful and the transfer of $\mathrm{SnO}_{2} \mathrm{NP}$ only worked when applying a second laser pulse to improve the adhesion.

\subsection{Transfers under optimal conditions}

Transfers with an optimal fluence were performed with all the different systems onto substrates described in Sect. 2.3 with a sensor-like electrode design. The material was transferred onto glass and on platinum for transfer characterization and onto the IDT structure for sensing tests. After the transfer, the samples were conditioned in order to decompose and cure the transferred material. Images of transfers of all the different systems on the glass part are shown in Fig. 4 labeled with the transfer fluence and the averaged height of the pixels. The height of the transferred pixels was measured with a profilometer after the samples were conditioned. All the pixels have a large surface roughness (see Fig. 5 as an

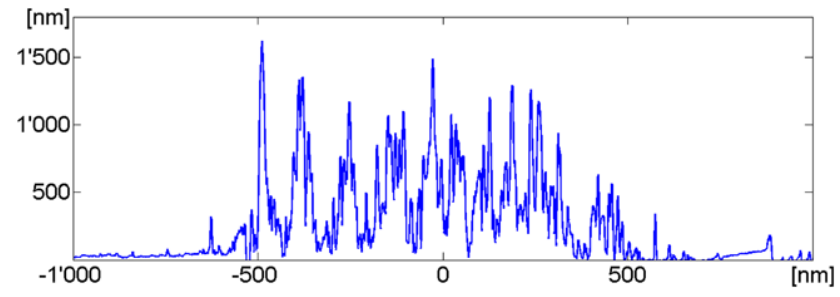

Fig. 5 Thickness profile of transferred pixel of $\mathrm{SnCl}_{2}(\mathrm{acac})_{2}-\mathrm{I}$

example) and to determine the pixels height the profile was averaged over the entire pixel. The large errors are due to samples with not so well-defined pixel borders, which made the averaging inaccurate.

Transfers of $\mathrm{SnCl}_{2}(\mathrm{acac})_{2}$-I without a TP interlayer lead to well-defined pixels with a surface structure comparable to the donor film for transfers with one and two pulses. Transfers with TP don not lead to a well-defined transfer and a second laser pulse smears out the pixel even more, visible as a cloud of material around the transfer area. This is probably caused by a reablation and redeposition of the transferred material. $\mathrm{SnCl}_{2}$ (acac) $)_{2}$-I donor films are about $1 \mu \mathrm{m}$ thick while the transferred pixels are only $900 \mathrm{~nm}$ for single pulse transfer and $320 \mathrm{~nm}$ for two pulse transfer. Comparing the height of the samples shows that the material transferred with two pulses is significantly thinner than the ones with one pulse, which indicates an ablation of material with the second laser pulse.

The $\mathrm{SnCl}_{2}$ (acac) $)_{2}$-I donor film on $200 \mathrm{~nm}$ TP with a total thickness of $1.2 \mu \mathrm{m}$ has the same amount of active material. A single pulse transfer leads to a pixel with a similar thickness than for a transfer without TP, however, transfers of these films are not as homogeneous and optically sharp than transfers without TP. Transfers with two pulses smear out the pixel even more and the variation in thickness increases such that a reproducible transfer with these conditions is not achievable. 

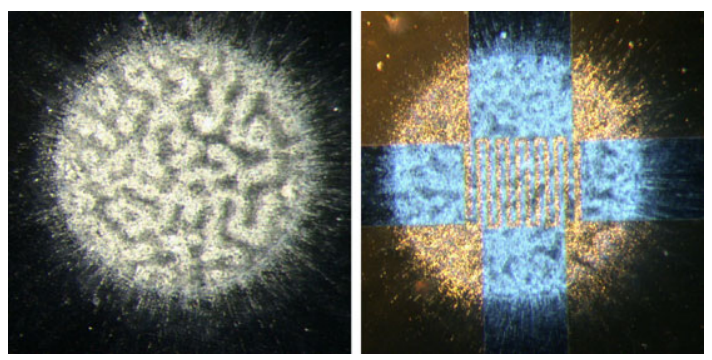

Fig. 6 Transfers of $\mathrm{SnCl}_{2}(\mathrm{acac})_{2}$-I onto glass and onto the IDT (glass/platinum) do not show a significant difference

Donor films of $\mathrm{SnCl}_{2}$ (acac) $)_{2}$-II spin coated on quartz and on TP have a similar thickness of $650 \mathrm{~nm}$ and $700 \mathrm{~nm}$, respectively. Transfers with and without TP and one laser pulse result in optically comparable pixels with well-defined edges. The transfer with TP results in pixels with the same thickness as the donor film. On the other hand, transfers without TP are about $150 \mathrm{~nm}$ thinner than the donor film suggesting a strong pixel decomposition or lower adhesion.

Transfers with two laser pulses smear out the edges. The additional energy moves material away from the transfer area resulting in a halo around the pixel (see Fig. 4). The halo gives a rise to the large error in thickness determination. Taking this variation into account, the pixels transferred with two pulses have roughly the same thickness as pixels transferred with one pulse. A better sticking with the second laser pulse is not observed.

Successful transfer of $\mathrm{SnO}_{2} \mathrm{NP}$ is only possible with two pulses and a TP interlayer. The transferred $\mathrm{SnO}_{2} \mathrm{NP}$ layer has, compared to the transfers of $\mathrm{SnCl}_{2}(\mathrm{acac})_{2}$ systems, well-defined edges. $\mathrm{SnO}_{2}$ is a stable material and cannot be decomposed further by the second laser pulse. The experiments indicate that the second laser pulse just improves the adhesion of the transferred material caused by a local heating of the NP. The surface of the transferred pixels is rougher than the donor film. With a thickness of $200 \mathrm{~nm}$, the transferred pixel is thicker than the precursor material $(\approx 50 \mathrm{~nm}$ NP on $200 \mathrm{~nm}$ TP). Transfers onto the flat platinum part as well as onto the IDT structure do not show significant differences to the transfers onto glass. As a comparison, the transfers of $\mathrm{SnCl}_{2}(\mathrm{acac})_{2}$-I onto the IDT and onto the glass part are shown in Fig. 6 as an example where the difference in brightness is due to the different optical properties of the substrate (platinum which is reflecting and the transparent glass). The quality of the borders and the morphology are similar.

These data show that LIFT transfers onto different flat substrate materials work very well. Transferring onto the IDTs with a structure height comparable to the film thickness shows a similar behavior as the transfers on the flat surface. Even transfers of $\mathrm{SnO}_{2} \mathrm{NP}$ with a film thickness smaller than the IDTs structure height proved to be possible. To check whether the transferred films are electrically
Table 1 Resistance $R_{0}$ for all the different prepared samples measured at $385{ }^{\circ} \mathrm{C}$

\begin{tabular}{|c|c|c|c|c|}
\hline & $\begin{array}{l}\text { Average } \\
{[\Omega]}\end{array}$ & $\begin{array}{l}\text { Sample I } \\
{[\Omega]}\end{array}$ & $\begin{array}{l}\text { Sample II } \\
{[\Omega]}\end{array}$ & $\begin{array}{l}\text { Sample III } \\
{[\Omega]}\end{array}$ \\
\hline \multicolumn{5}{|c|}{$\mathrm{SnCl}_{2}(\mathrm{acac})_{2}-\mathrm{I}$} \\
\hline $1 \mathrm{P}$ & $2.92 \times 10^{5}$ & broken & $2.18 \times 10^{5}$ & $3.65 \times 10^{5}$ \\
\hline $2 \mathrm{P}$ & $1.07 \times 10^{7}$ & $1.91 \times 10^{7}$ & $9.45 \times 10^{6}$ & $3.67 \times 10^{6}$ \\
\hline TP 1P & $1.06 \times 10^{7}$ & $4.91 \times 10^{6}$ & $4.15 \times 10^{6}$ & $2.27 \times 10^{7}$ \\
\hline TP 2P & $3.92 \times 10^{7}$ & $3.92 \times 10^{7}$ & Not stable & Not stable \\
\hline \multicolumn{5}{|c|}{$\mathrm{SnCl}_{2}(\mathrm{acac})_{2}-\mathrm{II}$} \\
\hline $1 \mathrm{P}$ & $7.61 \times 10^{5}$ & $6.28 \times 10^{5}$ & $5.78 \times 10^{5}$ & $1.08 \times 10^{6}$ \\
\hline $2 \mathrm{P}$ & $7.84 \times 10^{6}$ & $8.19 \times 10^{6}$ & $\begin{array}{l}\text { Short } \\
\text { circuit }\end{array}$ & $8.08 \times 10^{5}$ \\
\hline TP 1P & $1.61 \times 10^{6}$ & $3.93 \times 10^{5}$ & $3.84 \times 10^{6}$ & $5.90 \times 10^{5}$ \\
\hline TP 2P & $2.08 \times 10^{6}$ & $1.95 \times 10^{6}$ & $2.08 \times 10^{6}$ & $2.23 \times 10^{6}$ \\
\hline \multicolumn{5}{|c|}{$\mathrm{SnO}_{2}-\mathrm{NP}$} \\
\hline TP 2P & $2.36 \times 10^{9}$ & $1.41 \times 10^{9}$ & $1.94 \times 10^{9}$ & $4.05 \times 10^{9}$ \\
\hline
\end{tabular}

interconnected and if it is suitable for sensing applications, the conductivity of the transferred material has to be measured.

\subsection{Conductivity of the transferred material}

The conductivities of all the above described transfers were measured at a temperature of $385 \pm 5{ }^{\circ} \mathrm{C}$. Average values for the different prepared $\mathrm{SnO}_{2}$ pixels as well as individual sample values are shown in Table 1 . The resistance of the individual samples was determined after the samples were stabilized. The listed $R_{0}$ values are the average over a time period of $2 \mathrm{~min}$. Drift over larger time scales, hours to days, are not taken into account.

All the transferred samples are conductive with a stable $R_{0}$ except $\mathrm{SnCl}_{2}$ (acac) $)_{2}$-I on TP transferred with 2 pulses where already the optical appearance indicated an incomplete layer. All the other samples were conductive in the range of $200 \mathrm{k} \Omega$ to $4 \mathrm{G} \Omega$. There is a clear difference in the average resistance between the differently prepared and transferred samples as well as the variation of $R_{0}$ of the individual samples within the same system. A main factor influencing the difference between $\mathrm{SnO}_{2}$ from $\mathrm{SnCl}_{2}$ (acac) 2 with $R_{0}$ of $200 \mathrm{k} \Omega$ to $22 \mathrm{M} \Omega$ compared to $\mathrm{SnO}_{2}$ NP with a resistance range two orders of magnitude higher $(1.5-4 \mathrm{G} \Omega$ ) is the different film thickness. The very thin $\mathrm{SnO}_{2} \mathrm{NP}$ films, which are even thinner than the height difference on the IDT, are probably not well interconnected and, therefore, the conductivity is limited.

$\mathrm{SnCl}_{2}$ (acac) $)_{2}$-I transferred with one pulse and no TP shows with $3 \times 10^{5} \Omega$ the lowest resistance of all measured samples. The variation in $R_{0}$ and thickness between individual samples of $\mathrm{SnCl}_{2}$ (acac) $)_{2}$-I transferred with one pulse is small. Transfers of $\mathrm{SnCl}_{2}(\mathrm{acac})_{2}$ with 1 pulse and TP and 2 
pulses without TP have similar values and variations in $R_{0}$ even if the thickness of these two systems is a factor of 3 different. Transfers without TP and 2 pulses have a too low success, meaning the resistance is measurable but changing strongly over short time periods and, therefore, no adequate conclusion can be made.

$\mathrm{SnCl}_{2}(\mathrm{acac})_{2}$-II samples transferred with and without TP, single or double pulses show in the error range a similar value for $R_{0}$ of around $3 \mathrm{M} \Omega(0.4$ to $8 \mathrm{M} \Omega$ ). Comparing the scattering of the individual $R_{0}$ shows that samples where the $\mathrm{SnCl}_{2}$ (acac) $)_{2}$-II interacts with one laser pulse (single pulse no TP and double pulse with TP) have $R_{0}$ values with similar values. For the samples where $\mathrm{SnCl}_{2}(\mathrm{acac})_{2}$ is not interacting with the laser (single pulse with $\mathrm{TP}$ ) and where it interacts with 2 pulses (double pulse no TP), the scattering of $R_{0}$ values are significantly larger.

All the analyzed $\mathrm{SnO}_{2}$ systems show a resistance, which is in the required range for sensing applications. Pixels based on $\mathrm{SnCl}_{2}(\mathrm{acac})_{2}$ transferred with a single pulse and without TP show for both materials the lowest resistance. This might be caused by a larger surface area which results in a high conductivity at elevated temperatures. Applying a second laser pulse or transferring the material with the help of TP leads to a different surface morphology and may be also a different composition and, therefore, to a different conductivity. Further analysis of the sensitivity of the differently prepared and transferred $\mathrm{SnO}_{2}$ toward various analytes are needed in order to determine the commercial potential of LIFT for a industrial sensor production.

\subsection{Sensitivity}

To test the sensing capability of the transferred material, the same setup as for the resistivity measurements was used. Additional to the constant flow of dry synthetic air $(51 / \mathrm{min})$ $0.1 \mathrm{ml}$ of solvent was injected into the hot oven. The solvent evaporated in the hot tube and the vapor got transported with the gas to the materials surface. The exact solvent concentration is unknown, but it is estimated to be in the low percentage range. To analyze the sensing capability, the LIFTed sensor pads were exposed to ethanol, acetone, and methanol in consecutive order to see a resistance drop and with it the capability of sensing different gases. The response of a $\mathrm{SnCl}_{2}$ (acac) $)_{2}$-I sample, transferred with a single pulse, toward ethanol, acetone, and methane is shown in Fig. 7.

The sample temperature was around $510{ }^{\circ} \mathrm{C}$ leading to a $R_{0}$ of $3 \mathrm{k} \Omega$ which is one order of magnitude lower than listed in Table $1,\left(T=385^{\circ} \mathrm{C}\right)$, but this is probably due to the higher temperature. The higher temperature for this measurement was chosen as at this temperature it is possible to detect also rather unreactive chemicals, such as $\mathrm{CH}_{4}$ which are more difficult to oxidize. The initial resistance recovered after each measurement back to the initial value as all these

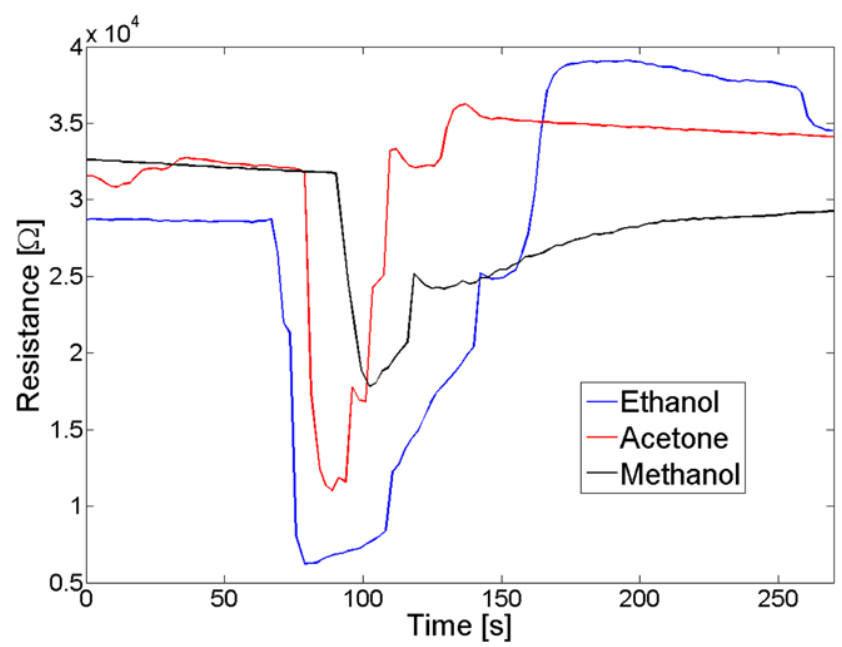

Fig. 7 Resistance change with $0.1 \mathrm{ml}$ solvent injected into the tube oven at a temperature of $\approx 510{ }^{\circ} \mathrm{C}$ of a $\mathrm{SnCl}_{2}(\mathrm{acac})_{2}$-I sample. Large drop in resistance for ethanol, acetone, and methane in descending order

measurements were carried out one after each other with the same sample.

The response to the three solvents is rather large with significant differences between the different analytes. Ethanol, the molecule which is easiest to oxidize, gives rise to the largest resistance drop as well as the longest response. The recovery of the initial $R_{0}$ value is reached just below $3 \mathrm{~min}$ after the injection while the resistance after the drop rose to a slightly higher value. This higher resistance could be caused by a slight cooling at the sensor surface which can not be detected with our setup.

The signal response to acetone is similar but with a much faster recovery of the initial $R_{0}$ value. The evaporation temperature of acetone is lower and the vapor pressure higher than for ethanol. This suggests that the concentration of acetone for a short period of time is much higher at the sensor leading to a comparable strong signal, but also a faster recovery time.

The vapor pressure and the evaporation temperature of methanol are between the values of ethanol and acetone; however, the molecule is chemically more stable than the other two. Therefore, the initial response to the injection is slower (rising edge) compared to the other two analytes. The total resistance drop is also the smallest on and the recovery is very slow. This might be due to the slow decomposition of adsorbed methanol on the $\mathrm{SnO}_{2}$ surface keeping the resistance low for more than 2 minutes.

These measurements show that the transferred materials are sensitive to different organic vapors. For a proper analysis of the sensitivity, the exact concentration has to be adjustable. The differently prepared samples have to be tested for different analytes using different sample temperatures to find the best suited precursor material for sensors prepared by LIFT. 


\section{Conclusion}

It has been shown that functional $\mathrm{SnO}_{2}$ can be transferred using the reactive LIFT technique. In reactive LIFT, the capability of transferring materials with a high spatial resolution together with the ability of changing the material with the UV laser light was combined. $\mathrm{SnCl}_{2}$ (acac) $)_{2}$, synthesized by two methods, as well as $\mathrm{SnO}_{2} \mathrm{NP}$ were transferred with one and two laser pulses onto sensor-like test structures. While $\mathrm{SnCl}_{2}$ (acac) $)_{2}$ can be transferred with one and two laser pulses and with and without the TP interlayer transferring the $\mathrm{SnO}_{2} \mathrm{NP}$ needs a second laser pulse to improve the adhesion onto the receiver substrate and the TP layer, which also protects the quartz donor substrate from getting damaged. $\mathrm{SnCl}_{2}(\mathrm{acac})_{2}$ based transfers have a very high success rate concerning transfer quality and conductivity.

The conductivity of the transferred material was measured at a sample temperature of $385^{\circ} \mathrm{C}$. The resistances of all successfully transferred $\mathrm{SnO}_{2}$ layers are in the range of $200 \mathrm{k} \Omega$ to $4 \mathrm{G} \Omega$. The $R_{0}$ values of the $\mathrm{SnCl}_{2}(\mathrm{acac})_{2}$ based systems are in the range to be used on a commercial sensor without changing design or parts of the electronics.

First sensitivity tests with ethanol, acetone, and methanol as analytes were carried out. The transferred material showed a large resistance drop for all three tested substances. This study is a proves the possibility of using LIFT to print $\mathrm{SnO}_{2}$ based on different precursor materials for sensing applications.

Acknowledgements The authors would like to thank Ulrike Lehmann and Alain Grisel (Microsens) for designing and producing the sensor-like microstructures. Additionally, we like to thank Michael Horisberger (PSI) for sputtering the $\mathrm{SnO}_{2}$ donor substrates. Funding for this research was provided by the European Commission7th Framework Programme (FP7-ICT project No. 247868) e-LIFT.

\section{References}

1. N. Yamazoe, G. Sakai, K. Shimanoe, Catal. Surv. Asia 7(1), 63 (2003)

2. K. Sahner, H. Tuller, J. Electroceram. 24(3), 177 (2010)
3. W. Shen, Sens. Actuators B, Chem. 166-167(0), 110 (2012)

4. J. Bohandy, B.F. Kim, F.J. Adrian, J. Appl. Phys. 60(4), 1538 (1986)

5. E. Touloupakis, C. Boutopoulos, K. Buonasera, I. Zergioti, M. Giardi, Anal. Bioanal. Chem. 402(10), 3237 (2012)

6. V. Dinca, R. Fardel, J. Shaw-Stewart, F. Di Pietrantonio, D. Cannata, M. Benetti, E. Verona, A. Palla-Papavlu, M. Dinescu, T. Lippert, Sens. Lett. 8, 436 (2010)

7. V. Dinca, A. Palla-Papavlu, M. Dinescu, J. Shaw-Stewart, T. Lippert, F. Di Pietrantonio, D. Cannata, M. Benetti, E. Verona, Appl. Phys. A, Mater. Sci. Process. 101(3), 559 (2010)

8. A. Palla-Papavlu, V. Dinca, M. Dinescu, F. Di Pietrantonio, D. Cannata, M. Benetti, E. Verona, Appl. Phys. A, Mater. Sci. Process. 105(3), 651 (2011)

9. A. Palla-Papavlu, I. Paraico, J. Shaw-Stewart, V. Dinca, T. Savopol, E. Kovacs, T. Lippert, A. Wokaun, M. Dinescu, Appl. Phys. A, Mater. Sci. Process. 102(3), 651 (2011)

10. V. Dinca, A. Palla-Papavlu, A. Matei, C. Luculescu, M. Dinescu, T. Lippert, F. Di Pietrantonio, D. Cannata, M. Benetti, E. Verona, Appl. Phys. A, Mater. Sci. Process. 101(2), 429 (2010)

11. D. Cannata, M. Benetti, F. Di Pietrantonio, E. Verona, A. PallaPapavlu, V. Dinca, M. Dinescu, T. Lippert, Sens. Actuators B, Chem. 173, 32 (2012)

12. F. Di Pietrantonio, M. Benetti, D. Cannata, E. Verona, A. PallaPapavlu, V. Dinca, M. Dinescu, T. Mattle, T. Lippert, Sens. Actuators B, Chem. 174, 158 (2012)

13. M. Nagel, R. Hany, T. Lippert, M. Molberg, F.A. Nuesch, D. Rentsch, Macromol. Chem. Phys. 208(3), 277 (2007)

14. J. Stebani, O. Nuyken, T. Lippert, A. Wokaun, Makromol. Chem., Rapid. Commun. 14, 365 (1993)

15. S.A. Kuznetsova, L.F. Ikonnikova, V.V. Kozik, Inorg. Mater. 43(6), 622 (2007)

16. A.G. Stepanov, V.M. Nekipelov, Russ. Chem. Bull. 36(11), 2403 (1987)

17. J. Shaw-Stewart, B. Chu, T. Lippert, Y. Maniglio, M. Nagel, F. Nuesch, A. Wokaun, Appl. Phys. A, Mater. Sci. Process. 105(3), $713(2011)$

18. R. Swanepoel, J. Opt. Soc. Am. A 2(8), 1339 (1985)

19. S. Capone, A. Forleo, L. Francioso, R. Rella, P. Siciliano, J. Spadavecchia, D.S. Presicce, A.M. Taurino, J. Optoelectron. Adv. Mater. 5(5), 1335 (2003)

20. M. Vrnata, V. Myslik, F. Vyslouzil, M. Jelinek, J. Lancok, J. Zemek, Sens. Actuators B, Chem. 71(1-2), 24 (2000),

21. J. Robertson, B. Falabretti, Electronic Structure of Transparent Conducting Oxides Handbook of Transparent Conductors (Springer, New York, 2010), pp. 27-50

22. J. Shaw-Stewart, T. Lippert, M. Nagel, F. Nuesch, A. Wokaun, Appl. Phys. Lett. 100(20), 203303 (2012)

23. R. Fardel, P. Feurer, T. Lippert, M. Nagel, F.A. Nuesch, A. Wokaun, Appl. Surf. Sci. 254(4), 1332 (2007) 